\section{ANÁLISE DA AÇÃO ANTIMICROBIANA DE CREMES DENTAIS INFANTIS DO MERCADO BRASILEIRO}

\author{
Analysis of the antimicrobial activity of children's dentifrices \\ of the Brazilian market
}

\author{
Análisis de la acción antimicrobiana de cremas dentales \\ infantiles del mercado brasileño
}

\section{RESUMO}

Objetivo: Avaliar a ação antimicrobiana de cremes dentais infantis do mercado brasileiro. Métodos: Estudo laboratorial realizado em uma universidade de Fortaleza/CE, em 2014, utilizou 12 placas de Petri com meios de cultura Muller Hinton para Streptococcus mutans e Agar Sabouraud para Candida albicans, nas quais poços contendo quantidades iguais de cremes dentais $\left(\right.$ Tandy $^{\circledR}$, Colgate Barbie ${ }^{\circledR}$, Oral B Stages ${ }^{\circledR}$, Bitufo Ben $10^{\circledR}$, Even Mônica ${ }^{\circledR}$, Boni Looney Tunes ${ }^{\circledR}$ com flúor, Malvatrikids Baby ${ }^{\circledR}$, Condor Tigor $^{\circledR}$, Even Baby ${ }^{\circledR}$, Bitufo Cocoricó $^{\circledR}$ e Sanifil Fase $1^{\circledR}$ sem flúor) foram semeados e incubados com Streotococcus mutans em jarra de anaerobiose, ambos em estufa bacteriológica a $37^{\circ} \mathrm{C}$, por 48 horas. Após esse período, analisou-se a formação ou não de halos de inibição, que representa a ação antimicrobiana. Resultados: Os resultados obtidos dos cremes dentais fluoretados e não fluoretados apresentaram diferenças discretas de medidas de halos de inibição entre si, mas os fluoretados mostraram atividade antimicrobiana contra as cepas avaliadas. Malvatrikids Baby ${ }^{\circledR}$, Even Baby ${ }^{\circledR}$ e Sanifil Fase $1{ }^{\circledR}$ não mostraram atividade contra Streptococcus mutans e somente o Sanifil Fase $1^{\circledR}$ não apresentou contra Candida albicans. Conclusão: Todos os cremes dentais fluoretados avaliados e dois sem flúor (Condor Tigor ${ }^{\circledR}$ e Bitufo Cocoricó ${ }^{\circledR}$ ) apresentaram atividade antimicrobiana contra as cepas avaliadas.

Descritores: Dentifrícios; Produtos com Ação Antimicrobiana; Candida; Streptococcus mutans.

\section{ABSTRACT}

Objective: To evaluate the antimicrobial activity of children's toothpastes of the Brazilian market. Methods: Experimental study conducted in a university of Fortaleza, CE, Brazil, in 2014, using 12 Petri dishes with culture media Mueller Hinton for Streptococcus mutans, and Sabouraud Agar for Candida albicans, where wells containing equal amounts of toothpaste $\left(\right.$ Tandy $^{\circledR}$, Colgate Barbie ${ }^{\circledR}$, Oral B Stages ${ }^{\circledR}$, Bitufo Ben $10^{\circledR}$, Even Mônica ${ }^{\circledR}$, Boni Looney Tunes $^{\circledR}$ with fluoride, Malvatrikids Baby ${ }^{\circledR}$, Condor Tigor ${ }^{\circledR}$, Even Baby ${ }^{\circledR}$, Bitufo Cocoricó ${ }^{\circledR}$ and Sanifil Fase $1^{\circledR}$ without fluoride) were seeded and incubated with Streptococcus mutans in anaerobic jars, both in bacteriological incubator at $37^{\circ} \mathrm{C}$, for $48 \mathrm{~h}$. After this period, it was examined whether or not there was formation of inhibition zones, which represent the antimicrobial activity. Results: The results of fluoride and non-fluoride toothpastes showed discrete differences in inhibition zones measures compared to each other, but the ones with fluoride presented antimicrobial activity against the evaluated strains. Malvatrikids Baby ${ }^{\mathbb{B}}$, Even Baby ${ }^{\circledR}$ and Sanifil Fase $1^{\circledR}$ showed no activity against Streptococcus mutans, and the last did not have effect against Candida either. Conclusion: All fluoride toothpastes evaluated and two of those without fluoride (Condor Tigor ${ }^{\circledR}$ e Bitufo Cocoricó ${ }^{\circledR}$ ) showed antimicrobial activity against the evaluated strains.

Descriptors: Dentifrices; Products with Antimicrobial Action; Candida; Streptococcus mutans.
Artigo Original

Maria Laiz Moreira de Souza ${ }^{(1)}$

Giulianna Bezerra Gomes ${ }^{(1)}$

Sérgio Luis da Silva Pereira ${ }^{(1)}$

Márcia Maria de Negreiros Pinto

Rocha $^{(1)}$

Paula Borges Jacques ${ }^{(1)}$

1) Universidade de Fortaleza - UNIFOR Fortaleza (CE) - Brasil

Recebido em: 24/11/2015

Revisado em: 03/12/2015

Aceito em: 28/12/2015 


\section{RESUMEN}

Objetivo: Evaluar la acción antimicrobiana de las cremas dentales infantiles del mercado brasileño. Métodos: Estudio de laboratorio realizado en una universidad de Fortaleza/CE, en 2014 que utilizó 12 placas de Petri con medios de cultivo Muller Hinton para el Streptococcus mutans y Agar Sabouraud para la Candida albicans las cuales pozos con cantidades iguales de cremas dentales (Tandy ${ }^{\circledR}$, Colgate Barbie ${ }^{\circledR}$, Oral B Stages ${ }^{\circledR}$, Bitufo Ben $10^{\circledR}$, Even Mônica ${ }^{\circledR}$, Boni Looney Tunes ${ }^{\circledR}$ con flúor, Malvatrikids Baby ${ }^{\circledR}$, Condor Tigor ${ }^{\circledR}$, Even Baby ${ }^{\circledR}$, Bitufo Cocoricó ${ }^{\circledR}$ y Sanifil Fase $1^{\circledR}$ sin flúor) fueron incubados con Streptococcus mutans en una jarra anaeróbica, ambos en una estufa bacteriologica de $37^{\circ} \mathrm{C}$ durante 48 horas. Después de ese periodo se analizó la formación o no de halos de inhibición que representa la acción antimicrobiana. Resultados: Los resultados obtenidos con las cremas dentales con y sin flúor presentaron diferencias discretas de las medidas de halos de inhibición entre ellos pero las con flúor mostraron actividad antimicrobiana contra las cepas evaluadas. Malvatrikids Baby ${ }^{\circledR}$, Even Baby ${ }^{\circledR}$ y Sanifil Fase $1^{\circledR}$ no mostraron actividad contra el Streptococcus mutans, y solamente el Sanifil Fase $1^{\circledR}$ no la presentó contra la Candida albicans. Conclusión: Todas las cremas dentales con flúor evaluadas y dos sin flúor (Condor Tigor ${ }^{\circledR}$ y Bitufo Cocoricó $^{\circledR}$ ) presentaron actividad antimicrobiana contra las cepas evaluadas.

Descriptores: Dentífricos; Productos con Acción Antimicrobiana; Candida; Streptococcus mutans.

\section{INTRODUÇÃO}

A cárie dentária é considerada uma das patologias mais prevalentes no mundo e um problema de saúde pública. De origem infecciosa e caracterizada pela perda mineral da estrutura dental, tem relação íntima com a presença do biofilme dental, sendo a principal responsável por grandes perdas dentárias ${ }^{(1-3)}$. No Brasil, observou-se o declínio da cárie com o auxílio de vários fatores, entre os quais estão: a descentralização de serviços públicos, com a inclusão da equipe da saúde bucal na Estratégia de Saúde da Família ${ }^{(4)}$; a fluoretação da água de abastecimento público; e o uso regular de cremes dentais com flúor em sua composição(5).

$\mathrm{O}$ acúmulo de bactérias e outros micro-organismos formando uma comunidade sobre a superfície dentária pode ser previamente evitado ou tardiamente tratado, tendo como principal mecanismo de prevenção a escovação mecânica, impedindo a ação das bactérias e evitando, assim, a desmineralização do esmalte ${ }^{(3,6)}$.

Como forma de diminuir a prevalência e o alto risco de cárie ${ }^{(7)}$, indicam-se agentes químicos que atuam sobre o biofilme, interferindo na adesão bacteriana à superfície dental. O principal meio com agente químico que auxilia na remoção do biofilme para uso caseiro, recomendado por profissionais da Odontologia, é a escovação dentária com creme dental ou dentifrício ${ }^{(6)}$, sendo este qualquer preparação utilizada na higiene bucal. Ele pode conter em sua composição abrasivo, detergente, aglutinante, flavorizante, medicamentos preventivos contra cárie, sendo encontrado na forma líquida, em pasta, gel ou pó(8).

$\mathrm{O}$ creme dental infantil vem sendo modificado ao longo da história ${ }^{(7)}$ para ser melhor utilizado e eficaz. No passado, apenas os com alto teor de flúor eram introduzidos no mercado, apresentando um papel importante no combate à cárie $^{(9)}$, por atuarem remineralizando a superfície do esmalte dentário e inibindo a desmineralização, mantendo o equilíbrio entre as estruturas mineralizadas do dente ${ }^{(10)}$.

Entretanto, quando da ingestão de flúor ${ }^{(11)}$, há risco de o paciente apresentar toxicidade aguda se grande quantidade for ingerida de uma só vez, manifestando-se clinicamente desde dores abdominais até parada cardiorrespiratória, ou toxicidade crônica, a fluorose, um efeito indesejável que pode causar manchas no esmalte dentário quando participa da formação dentária em alta quantidade ${ }^{(11)}$.

Para diminuir-se, então, o risco de fluorose com a ingestão acidental de dentifrício contendo alto teor de flúor, foram inseridos no mercado dentifrícios com pouca quantidade desse fármaco, e logo após, os totalmente sem flúor, indicados para os bebês. Estes têm a substância flúor substituída por agentes terapêuticos, como a camomila, as enzimas, o xilitol, dentre outros ${ }^{(12)}$. A promessa era controlar a cárie, diminuir os micro-organismos bucais e servir como método de motivação para a higiene bucal de bebês e crianças ${ }^{(12)}$.

A partir dos anos 1980, com o aumento considerável de dentifrícios fluoretados, a cárie decaiu em países desenvolvidos, e após dez anos, esse mesmo declínio foi notado no Brasil ${ }^{(3,13)}$, evidenciando que o uso de flúor em alta frequência e baixa concentração, através da escovação dentária com dentifrícios contendo a concentração preconizada, de 1000 a 1500 ppm, é eficaz no controle da cárie, sendo imprescindível para a promoção da saúde ${ }^{(2,3,9)}$.

Ocorre que o mercado brasileiro foi tomado por diferentes tipos de dentifrícios destinados ao público infantil: os que têm flúor na quantidade ideal para o controle da cárie, aqueles que contêm pouca quantidade de flúor, e, ainda, os que são isentos de flúor em sua composição ${ }^{(14)}$, tendo sido recentemente apontado que há necessidade de se modificar a atual legislação brasileira quanto ao mercado de cremes dentais ${ }^{(15)}$, pois fica difícil serem selecionados e utilizados, visto que os pais ou responsáveis nem sempre sabem qual o risco de cárie a que seus filhos estão sujeitos nem possuem o conhecimento acerca do potencial que esses diferentes tipos de dentifrícios apresentam no controle do biofilme dental, ou, ainda, se podem apresentar risco à saúde de seus filhos com a substituição de fármacos ${ }^{(16)}$. 
Diante da escassez de avaliações laboratoriais com comprovações científicas da eficácia contra o crescimento microbiano dos dentifrícios infantis disponíveis no mercado nacional, contendo vários princípios ativos em suas formulações ${ }^{(15-17)}$, o objetivo do presente estudo foi avaliar a ação antimicrobiana de cremes dentais infantis do mercado brasileiro.

\section{MÉTODOS}

Estudo laboratorial e microbiológico realizado em uma universidade particular da capital do estado do Ceará, Brasil. Para a presente pesquisa, selecionaram-se 11 dentifrícios infantis de diferentes marcas/fabricantes e facilmente encontrados no mercado brasileiro, comprados

Quadro I - Descrição dos cremes dentais infantis (dentifrícios) investigados, de acordo com fabricante e componentes. Fortaleza, CE, 2014.

\begin{tabular}{|c|c|c|c|}
\hline & Dentifrícios & Fabricante & Componentes \\
\hline $\mathbf{A}$ & $\begin{array}{l}\text { Tandy } \\
\text { - sabor } \\
\text { morango }\end{array}$ & $\begin{array}{l}\text { Colgate-Palmolive } \\
\text { Industrial Ltda. - } \\
\text { Brasil }\end{array}$ & $\begin{array}{l}\text { Sorbitol, água, sílica hidratada laurilsulfato de sódio, PEG-12, goma de } \\
\text { celulose, aroma, sacarina sódica, corante; fluoreto de sódio (1100 ppm). }\end{array}$ \\
\hline B & $\begin{array}{l}\text { Colgate } \\
\text { Smiles } \\
\text { Barbie }^{\circledR}\end{array}$ & $\begin{array}{l}\text { Mission Hills para } \\
\text { Colgate-Palmolive - } \\
\text { México }\end{array}$ & $\begin{array}{l}\text { Sorbitol, água, sílica hidratada, laurilsulfato de sódio, PEG-12, goma } \\
\text { de celulose, sabor, sacarina sódica, dióxido de titânio, corante rojo, } \\
\text { dispenteno, cinamaldeído, eugenol; fluoreto de sódio (1100 ppm). }\end{array}$ \\
\hline C & $\begin{array}{l}\text { Oral B Stages } \\
\text { Pooh }^{\circledR}\end{array}$ & $\begin{array}{l}\text { Procter \& Gamble } \\
\text { Manucfatura - } \\
\text { México }\end{array}$ & $\begin{array}{l}\text { Sorbitol, água, sílica hidratada, laurilsulfato de sódio, goma de celulose, } \\
\text { aroma, sacarina sódica, carbômero, pirofosfato dissódico, hidróxido de } \\
\text { sódio, corante; fluoreto de sódio ( } 500 \mathrm{ppm}) \text {. }\end{array}$ \\
\hline D & $\begin{array}{l}\text { Bitufo } \\
\text { Ben } 10^{\circledR}\end{array}$ & $\begin{array}{l}\text { Cosmed Indústria } \\
\text { de Cosméticos e } \\
\text { Medicamentos - } \\
\text { Brasil }\end{array}$ & $\begin{array}{l}\text { Sorbitol, água, sílica hidratada, laurilsulfato de sódio, carbonato de } \\
\text { cálcio, carboximetilcelulose, polietilenoglicol, aroma, xilitol, silicato de } \\
\text { sódio, sacarina sódica, metilparabeno, propilparabeno, pigmento verde, } \\
\text { d-limoneno, monofluorfosfato de sódio. }\end{array}$ \\
\hline $\mathbf{E}$ & $\begin{array}{l}\text { Even - Turma } \\
\text { da Mônica }\end{array}$ & $\begin{array}{l}\text { Indústrias Reunidas } \\
\text { Raymundo da Fonte } \\
\text { - Brasil }\end{array}$ & $\begin{array}{l}\text { Sorbitol, água, sílica, glicerina, laurilsulfato de sódio, sacarina sódica, } \\
\text { carboximetilcelulose, polietilenoglicol, sorbato de potássio, corante, } \\
\text { aroma, monofluorfosfato de sódio (1100 ppm). }\end{array}$ \\
\hline $\mathbf{F}$ & $\begin{array}{l}\text { Boni - Looney } \\
\text { Tunes }^{\circledR}\end{array}$ & $\begin{array}{l}\text { Laboratório } \\
\text { Boniquet do Brasil } \\
\text { - Brasil }\end{array}$ & $\begin{array}{l}\text { Sorbitol, água, sílica hidratada, sacarina sódica, metilparabeno, } \\
\text { propilparabeno, goma de celulose, PGE- } 8 \text {, sabor, glicerofosfato de cálcio, } \\
\text { dióxido de titânio, fluoreto de sódio (1100 ppm). }\end{array}$ \\
\hline G & $\begin{array}{l}\text { Malvatrikids } \\
\text { Baby }^{\circledR}\end{array}$ & $\begin{array}{l}\text { Laboratório Daudt } \\
\text { Oliveira - Brasil }\end{array}$ & $\begin{array}{l}\text { Sorbitol, água, sucralose, xilitol, goma de celulose, glicerina, extrato de } \\
\text { malva silvestris, sílica, benzoato de sódio, aroma, laurilsarcossinato de } \\
\text { sódio. }\end{array}$ \\
\hline H & $\begin{array}{l}\text { Condor - } \\
\text { Tigor Baby }\end{array}$ & $\begin{array}{l}\text { Dental Prev } \\
\text { Indústria e comércio } \\
\text { - Brasil }\end{array}$ & $\begin{array}{l}\text { Sorbitol, água, sílica, laurilsulfato de sódio, sacarina sódica, benzoato de } \\
\text { sódio, carboximetilcelulose, aroma. }\end{array}$ \\
\hline I & Even Baby ${ }^{\circledR}$ & $\begin{array}{l}\text { Indústrias Reunidas } \\
\text { Raymundo da Fonte } \\
\text { S/A - Brasil }\end{array}$ & $\begin{array}{l}\text { Sorbitol, glicerina, sacarina sódica, sílica, xilitol, carboximetilcelulose, } \\
\text { aroma, polietilenoglicol, sorbato de potássio, laurilsulfato de sódio, } \\
\text { corante, água. }\end{array}$ \\
\hline $\mathbf{J}$ & $\begin{array}{l}\text { Bitufo } \\
\text { Cocoricó }^{\circledR}\end{array}$ & $\begin{array}{l}\text { Cosmed Indústria } \\
\text { de Cosméticos e } \\
\text { Medicamentos - } \\
\text { Brasil }\end{array}$ & $\begin{array}{l}\text { Sorbitol, água, sílica hidratada, sacarina sódica, glicerina, laurilsulfato de } \\
\text { sódio,álcool, polietilienoglicol } 400 \text {, triclosan, xilitol, carboximetilceculose, } \\
\text { aroma, goma xantana, dióxido de titânio, EDTA de cálcio e sódio, } \\
\text { metilparabeno, propilparabeno. }\end{array}$ \\
\hline $\mathbf{L}$ & $\begin{array}{l}\text { Sanifil Fase } \\
1^{\circledR}\end{array}$ & $\begin{array}{l}\text { Cosmed Indústria } \\
\text { de Cosméticos e } \\
\text { Medicamentos - } \\
\text { Brasil }\end{array}$ & $\begin{array}{l}\text { Sorbitol, água, sílica hidratada, extrato de camomila, aroma, goma xantana, } \\
\text { benzoato de sódio, sacarina sódica, corante amarelo, corante azul. }\end{array}$ \\
\hline
\end{tabular}


em farmácias e supermercados no mês de março de 2014. Todos foram adquiridos no mesmo mês, para que não houvesse interferência do tempo de armazenamento em prateleiras sobre a qualidade dos produtos.

A descrição dos materiais testados na atual pesquisa, bem como fabricante e componentes estão listados no Quadro I. Todos os materiais encontravam-se dentro da validade.

A fase experimental ocorreu no Laboratório de Microbiologia. Para a sua realização, as examinadoras estavam devidamente treinadas e fizeram uso de equipamentos de proteção individual (EPI); além disso, a bancada laboratorial utilizada para a pesquisa foi descontaminada com álcool $70 \%$ friccionado por três vezes sobre sua superfície.

O teste de inibição do crescimento microbiológico deuse por ágar-difusão no método do poço ${ }^{(6)}$, o qual ocorreu por meio da verificação da formação de halos de inibição de crescimento no contorno dos poços, sendo utilizado como controle positivo a substância clorexidina gel a $2 \%$ (Essência Farma-Brasil $^{\mathbb{}}$ ) e ausência de material como controle negativo.

As cepas de micro-organismos mais prevalentes na cavidade bucal de crianças e que são responsáveis pelo processo de cárie dentária são Streptococcus mutans e Candida albican ${ }^{(18,19)}$. Por essa razão, essas cepas foram as escolhidas para serem utilizadas na presente pesquisa, visando-se uma maior aproximação com a realidade da situação clínica.

O estudo ocorreu em 12 placas de Petri preparadas com meios de cultura Muller Hinton para Streptococcus mutans $(\mathrm{n}=6)$ e Agar Sabouraud para Candida albicans $(\mathrm{n}=6)$, ambas as cepas foram fornecidas pelo Laboratório de Microbiologia da Universidade de Fortaleza. Realizado em triplicata, os micro-organismos replicados previamente eram semeados nas placas contendo os meios específicos em ágar, antes da inserção dos cremes dentais infantis.

Nas placas de Petri contendo os meios mencionados, construíram-se poços de $4 \mathrm{~mm}$ de diâmetro e $5 \mathrm{~mm}$ de profundidade, com auxílio de uma ponteira plástica desinfetada com álcool $70 \%$, os quais foram preenchidos com 0,13 gramas de cada creme dental infantil investigado, de acordo com o Quadro 1, com auxílio de uma seringa Centrix ${ }^{\circledR}$ (DFL, Indústria e comércio S.A., Brasil).

Em seguida, incubaram-se as placas com Streptococcus mutans em jarra de anaerobiose a $37^{\circ} \mathrm{C}$, em estufa bacteriológica, por 48 horas, para esperar o crescimento bacteriano. As placas com Candida Albicans foram colocadas em estufa bacteriológica, aguardando-se 48 horas para a coleta dos resultados ${ }^{(20)}$.
Após o tempo determinado, ocorreu a constatação do crescimento microbiano nas placas de Petri e se houve inibição de crescimento por meio da formação de halo de inibição, que confirma a ação antimicrobiana do produto. Para enfatizar esse achado, houve mensuração dos halos formados, com auxílio de régua milimetrada, por duas examinadoras calibradas, anotando-se os dados em tabelas e estabelecendo-se uma média aritmética entre os valores.

\section{RESULTADOS}

Nas placas de Petri com Streptococcus mutans, observou-se, após 48 horas, a formação de halos de inibição, ou seja, encontrou-se ação antimicrobiana, nos seguintes cremes dentais infantis: A, B, C, D, E, F, H, J (Quadro 1) e no controle clorexidina gel a $2 \%$.

$\mathrm{Na}$ Tabela I, apresenta-se o resultado da aferição dos halos de inibição obtido pelas duas avaliadoras (em milímetros - mm) nos cremes dentais infantis fluoretados, e na Tabela II, apresenta-se o resultado dos cremes dentais infantis sem flúor, quando avaliados com Streptococcus mutans.

Tabela I - Medição dos halos de inibição (mm*) em Streptococcus mutans, em cremes dentais infantis (dentifrícios) fluoretados. Fortaleza, CE, 2014.

\begin{tabular}{cccc}
\hline Dentifrício & Examinador 1 & Examinador 2 & Média \\
\hline A & 9 & 9,6 & 9,3 \\
B & 9 & 10 & 9,5 \\
C & 10,6 & 11,3 & 10,9 \\
D & 8 & 8,3 & 8,1 \\
E & 8,3 & 8,3 & 8,3 \\
F & 9,6 & 10,3 & 9,9 \\
\hline
\end{tabular}

*mm: milímetros

Tabela II - Medição dos halos de inibição (mm) em Streptococcus mutans, em cremes dentais infantis (dentifrícios) não fluoretados. Fortaleza, CE, 2014.

\begin{tabular}{cccc}
\hline Dentifrício & Examinador 1 & Examinador 2 & Média \\
\hline G & 0 & 0 & 0 \\
H & 8,3 & 7,6 & 7,9 \\
I & 0 & 0 & 0 \\
J & 8,6 & 8,6 & 8,6 \\
L & 0 & 0 & 0 \\
\hline
\end{tabular}

*mm: milímetros

Nas placas de Petri contendo Candida albicans, houve formação de halos de inibição nos seguintes dentifrícios: A, B, C, D, E, F, G, H, I, J e no controle clorexidina gel a $2 \%$. As Tabelas III e IV apresentam a medição dos halos formados pelos cremes dentais infantis fluoretados e não fluoretados, quando testados contra Candida albicans. 
O dentifrício L (Sanifil Fase $1^{\circledR}$ ) não apresentou formação de halo de inibição, evidenciando que não houve ação antifúngica contra Candida albicans, nem antibacteriana contra Streptococcus mutans (Tabelas II e IV).

Os poços vazios, utilizados como controle negativo, não apresentaram formação de halos de inibição para as cepas avaliadas.

Tabela III - Medição dos halos de inibição (mm*) em Candida albicans, em cremes dentais infantis (dentifrícios) fluoretados. Fortaleza, CE, 2014.

\begin{tabular}{lccc}
\hline Dentifrício & Examinador 1 & Examinador 2 & Média \\
\hline A & 7,3 & 8 & 7,6 \\
B & 5,3 & 5,6 & 5,4 \\
C & 9 & 10 & 9,5 \\
D & 8 & 7 & 7,5 \\
E & 8,3 & 7,6 & 7,9 \\
F & 8,6 & 9 & 8,8 \\
\hline
\end{tabular}

*mm: milímetros

Tabela IV - Medição dos halos de inibição (mm*) em Candida albicans, em cremes dentais infantis (dentifrícios) não fluoretados. Fortaleza, CE, 2014

\begin{tabular}{lccc}
\hline Dentifrício & Examinador 1 & Examinador 2 & Média \\
\hline $\mathrm{G}$ & 6,6 & 6,6 & 6,6 \\
$\mathrm{H}$ & 6,6 & 7 & 6,8 \\
$\mathrm{I}$ & 7,6 & 7,6 & 7,6 \\
$\mathrm{~J}$ & 8,3 & 9 & 8,6 \\
$\mathrm{~L}$ & 0 & 0 & 0 \\
\hline
\end{tabular}

*mm: milímetros

Salienta-se que o controle clorexidina gel a $2 \%$ obteve média de $7 \mathrm{~mm}$ de halo de inibição nas placas com Streptococcus mutans e 13,1 mm de halo de inibição nas placas com Candida albicans.

\section{DISCUSSÃO}

Mesmo com a vasta importância da avaliação da atividade antimicrobiana nos cremes dentais infantis, ainda não foi estabelecida uma metodologia universal para tal processo ${ }^{(17)}$. Na realização da presente pesquisa, optou-se pela utilização de amostras de dentifrícios fluoretados e não fluoretados não diluídos para avaliar a atividade antimicrobiana simulando a condição real bucal, que preconiza colocar o dentifrício na escova sem molhar, concordando com um estudo realizado em 2011 ${ }^{(20)}$, ao contrário de outro estudo que utilizou dentifrícios diluídos ${ }^{(12)}$.
Os resultados do presente estudo mostraram que os cremes dentais infantis fluoretados Tandy sabor morango ${ }^{\circledR}$, Colgate Smilles Barbie ${ }^{\circledR}$, Oral B Stages ${ }^{\circledR}$, Bitufo Ben $10^{\circledR}$, Even turma da Mônica ${ }^{\circledR}$ e Boni Looney Tunes ${ }^{\circledR}$ obtiveram formação de halos de inibição diante das cepas de Streptococcus mutans de $8,1 \mathrm{~mm}$ a $10,9 \mathrm{~mm}$, comparados à clorexidina gel a $2 \%$, utilizada como controle positivo, com média de halo de $7 \mathrm{~mm}$. Os mesmos dentifrícios comparados às cepas de Candida albicans obtiveram resultados de 5,4 mm a 9,5 mm, também comparadas à clorexidina gel a $2 \%$, com 13,1 mm de halo de inibição.

Outros trabalhos em que o creme dental Tandy ${ }^{\circledR}$ foi avaliado demonstraram uma taxa inibitória excelente frente às cepas de Streptococcus mutans ${ }^{(10,12,13,17,20,21)}$. Uma investigação também verificou que o dentifrício Bitufo Ben $10^{\circledR}$ apresentou atividade antimicrobiana sobre Streptococcus mutans ${ }^{(21)}$.

Dentre os cremes dentais fluoretados testados na presente pesquisa, o que possui menor concentração de flúor relatada pelo fabricante é o Oral B Stages Pooh ${ }^{\circledR}$, contendo $500 \mathrm{ppm}$, e os demais apresentam $1100 \mathrm{ppm}$, informado pelos fabricantes. Uma maior quantidade de flúor poderia implicar em maior atividade antimicrobiana e maior eficácia no controle de cárie ${ }^{(9)}$.

$\mathrm{O}$ atual trabalho também evidenciou resultados para dentifrícios sem flúor frente às cepas clínicas de Candida albicans, em que Malvatrikids Baby ${ }^{\circledR}$, Condor Tigor Baby ${ }^{\circledR}$ e Even Baby ${ }^{\mathbb{B}}$ obtiveram resultados com semelhantes halos de inibição, em média de $6,6 \mathrm{~mm}$ a $7,6 \mathrm{~mm}$. O dentifrício Bitufo Cocoricó ${ }^{\circledR}$ mostrou o melhor resultado, com halo de $8,6 \mathrm{~mm}$. Já o creme dental Sanifil Fase $1^{\circledR}$ obteve o pior resultado, não demonstrando formação de halo de inibição, ou seja, não evidenciou ação antimicrobiana contra as cepas avaliadas na presente pesquisa. Os cremes dentais sem flúor Condor Tigor Baby ${ }^{\circledR}$ e Bitufo Cocoricó ${ }^{\circledR}$, testados com cepas clínicas de Streptococcus mutans, obtiveram resultados semelhantes, com média entre 7,9 $\mathrm{mm}$ e $8,6 \mathrm{~mm}$, na avaliação da presente pesquisa.

Ressalta-se que não foram encontradas na literatura evidências científicas recentes com os mesmos cremes dentais/dentifrícios infantis, dificultando a discussão dos achados da atual pesquisa, comparando-se as marcas em ensaios de ação antimicrobiana. Entretanto, outros dentifrícios sem flúor, como Weleda ${ }^{\circledR}$ e Baby Oral Gel ${ }^{\circledR}$, não formaram halos de inibição ${ }^{(20)} \mathrm{em}$ estudo realizado com o método do poço.

Adicionalmente, alguns componentes da formulação dos cremes dentais sem flúor podem apresentar atividade antimicrobiana, como EDTA (ácido etilenodiamino tetracético), triclosan, malva, adoçantes, corantes e 
parabenos. Cabe ressaltar que tais componentes podem oferecer risco à saúde das crianças ${ }^{(16)}$.

O dentifrício Bitufo Cocoricó ${ }^{\circledR}$ não fluoretado contém em sua fórmula o triclosan, um agente com potencial atividade antimicrobiana ${ }^{(22)}$, e o EDTA, para o qual foi comprovada a atividade antifúngica na desinfecção de canais radiculares ${ }^{(23)}$ durante o tratamento endodôntico, e não deveria ser utilizado na superfície do dente nem em mucosa durante escovação e higienização, visto ter poder ácido e probabilidade de ocasionar lesões.

Já a malva, componente do Malvatrikids Baby ${ }^{\circledR}$, não possui atividade antimicrobiana sobre as cepas de Candida albicans $^{(24)}$, concordando com os achados da presente pesquisa.

Publicação recente reforça o uso de cremes dentais fluoretados em pequena quantidade para crianças, para prevenção de cárie e fluorose ${ }^{(25)}$. Assim, uma formulação ideal de cremes dentais destinados ao público infantil deveria proporcionar saúde, e não trazer danos com componentes, bem como deveria maximizar a disponibilidade de flúor, minimizar a abrasividade e apresentar sabores adequados, para que pudesse proporcionar uma experiência agradável de escovação dental às crianças de várias idades, objetivando bons hábitos bucais no futuro e boa saúde bucal para a vida $^{(26)}$.

Sugere-se a necessidade de pesquisas que avaliem a atividade antimicrobiana de cremes dentais infantis, mesmo em estudos laboratoriais como o aqui realizado, e divulgação dos achados à área da saúde, para auxiliar na sinalização aos pais e profissionais do melhor tipo de creme dental/dentifrício para a promoção da saúde infantil, pois há uma vasta quantidade deles no mercado, confundindo o usuário.

\section{CONCLUSÃO}

Todos os cremes dentais infantis fluoretados avaliados e dois sem flúor (Condor Tigor $^{\circledR}$ e Bitufo Cocoricó ${ }^{\circledR}$ ) apresentaram atividade antimicrobiana contra as cepas avaliadas.

\section{REFERÊNCIAS}

1. Reis J, Melo P. A cárie dentária, uma doença infecciosa. Rev Port Saúde Pública. 2003;21(1):35-40.

2. Hamati F, Rocha JS, Baldani MH. Prevalência de cárie, dor e uso de serviços odontológicos por crianças em áreas com e sem Equipes de saúde Bucal na Estratégia Saúde da Família no município de Ponta Grossa, Paraná, Brasil. Rev Bras Pesqui Saúde. 2014;16(3):4857.
3. Maltz M, Jardim JJ, Alves LS. Health promotion and dental caries. Braz Oral Res. 2010;24(Suppl 1):18-25.

4. Stocco G, Baldani MH. O controle das consultas odontológicas dos bebês por meio da carteira de vacina: avaliação de um programa-piloto desenvolvido na Estratégia Saúde da Família em Ponta Grossa (PR, Brasil). Ciênc Saúde Coletiva. 2011;16(4):2311-21.

5. Narvai PC, Frazão P, Castellanos RA. Declínio na experiência de cárie em dentes permanentes de escolares brasileiros no final do século XX. Rey Odontol Soc. 1999;1(1/2):25-9.

6. Souza-Gugelmin MCM, Silva FWGP, Queiroz AM, Amaral THA. Avaliação da atividade antimicrobiana de dentifrícios infantis: estudo in vitro. Rev Fac Odontol Porto Alegre. 2006;47(3):10-3.

7. Bratthall D, Hänsel-Petersson G, Sundberg H. Reasons for the caries decline: what do the experts believe? Eur J Oral Sci. 1996;104(4 ( Pt 2)):416-22.

8. Descritores em Ciências da Saúde - Biblioteca Virtual em Saúde. Descritor português: Dentifrício [acesso em 2015 Set 13]. Disponível em: http://decs.bvs.br/cgibin/wxis1660.exe/decsserver/

9. Marinho VC, Higgins JP, Sheiham A, Logan S Fluoride toothpastes for preventing dental caries in children and adolescents. Cochrane Database Syst Rev. 2003;(1):CD002278.

10. Cury JA. Lima OB. Ingestão de flúor por crianças pela água e dentifrícios. Rev Saúde Pública. 2001;35(6):57681.

11. Zohoori FV, Duckworth RM, Omid N, O'Hare WT, Maguire A. Fluoridated toothpaste: usage and ingestion of fluoride by 4- to 6-yr-old children in England. Eur J Oral Sci. 2012;120(5):415-21.

12. Vieira DM, Hirata RJ, Schneider AR. Avaliação antimicrobiana de três dentifrícios para o uso infantil estudo in vitro. Rev Bras Odontol. 2008;65(1):52-6.

13. Cury JA, Negri HMD. Efeito dose-resposta de uma formulação de dentifrício com concentração reduzida de fluoreto - estudo in vitro. Pesq Odontol Bras. 2002; 16(4):361-5.

14. Walsh T, Worthington HV, Glenny AM, Appelbe P, Marinho VC, Shi X. Fluoride toothpastes of different concentrations for preventing dental caries in children and adolescents. Cochrane Database Syst Rev. 2010;(1):CD007868.

15. Cury JA, Calderelli PG, Tenuta LMA. Necessity to review the Brazilian regulation about fluoride 
toothpastes. Rev Saúde Pública. 2015;49(74):1-7.

16. Visser M. Warning: why you should atay away from most children's tootpaste [acesso em 2014 Mar 14]. Disponível em: http://www.growingupherbal.com/ dangers-of-childrens-toothpaste.

17. Modesto A, Lima KC, Uzeda M. Atividade antimicrobiana de três dentifrícios utilizados na higiene oral de bêbês: estudo in vitro. Rev Assoc Paul Cir Dent. 2001;55(1):43-8.

18. Kneist S, Borutta A, Sigusch BW, Nietzsche S, Küpper H, Kostrzewa M, Callaway A. First-time isolation of Candida dubliniensis from plaque and carious dentine of primary teeth. Eur Arch Paediatr Dent. 2015;16(4):365-70.

19. Carvalho FG, Silva DS, Hebling J, Spolidorio LC, Spolidorio DMP. Presence of mutans streptococci and Candida spp. in dental plaque/dentine of carious teeth and early childhood caries. Arch Oral Biol. 2006;51(11):1024-8.

20. Campos ASC, Fonseca L, Simões FXPC, Juiz PJL. Atividade antimicrobiana de dentifrícios fluoretados sobre streptococcus mutans: estudo in vitro. Rev Bras Pesqui Saúde. 2011;13(1):4-10.

21. Ramos IA, Cardoso AMR, Leite RB, Calvacanti YW, Calvacanti AL. Efeito inibitório de dentifrícios infantis sobre o crescimento de bactérias cariogênicas. Rev Ciências Médicas Biológicas. 2013;12(3):274-7.

22. Aquino DR, Cortelli JR, Faria IS. Ação antimicrobiana do triclosan sobre microbiota cariogênica. Rev Biociênc. 2004;10(1-2):79-86.
23. Sen BH, Akdeniz BG, Denizci AA. The effect of ethylenediamine-tetraacetic acid on Candida albicans. Oral Surg Oral Med Oral Pathol Oral Radiol Endod. 2000;90(5):651-5.

24. Matos BM, Deco CP, Oliveira LD, Jorge AOC, Balducci I, Koga-Ito CY. Comparação da atividade antimicrobiana de soluções de peróxido de hidrogênio e malva sobre cândida albicans. Braz Dent Sci. 2009;12(2):24-8.

25. Wright JT, Hanson N, Ristic H, Whall CW, Estrich CG, Zentz RR. Fluoride toothpaste efficacy and safety in children younger than 6 years - A systematic review. J Am Dent Assoc. 2014;145(2):182-9.

26. Stovell AG, Newton BN, Lynch RJM. Important considerations in the development of toothpaste formulations for children. Int Dent J. 2013;63(Suppl. 2):57-63.

\section{Endereço do primeiro autor:}

Maria Laiz Moreira de Souza

Rua Raimundo Saraiva Coelho, 294

Bairro: Aeroporto

CEP: 63020-730 - Fortaleza - CE - Brasil

E-mail:mlaiz@hotmail.com

\section{Endereço para correspondência:}

Paula Borges Jacques

Curso de Odontologia da Universidade de Fortaleza Av. Washington Soares, 1321/ Bloco O

Bairro: Edson Queiroz

CEP: 60811-905 - Fortaleza - CE - Brasil

E-mail: paulajacques@unifor.br 